\title{
Fibroelastoma or atheromatous plaque: a case report
}

\author{
Stanko Biočić, Diana Rudan*, Željko Đurašević, Josip Vincelj \\ University Hospital Dubrava, Zagreb, Croatia
}

Cardiac fibroelastoma is a rare, benign cardiac tumor. Usually, they arise from valvular endocardium and non-valvular location is rare ${ }^{1}$. Although transthoracic echocardiography is sufficient for diagnosis of most cardiac tumors, small tumors may be missed.

We describe an adult female patient who was clinically asymptomatic, but was submitted for the echocardiocraphic evaluation because of the high blood pressure. Transthoracic echocardiography showed a small lesion that was attached to the aortic wall near the aortic valve. In such a case, differential diagnosis consists of tumor, thrombus or atheromatous plaque and usually relies on localization of the structure and clinical presentation.

In conclusion, echocardiography represents an invaluable diagnostic tool for the detection of intracardiac masses while it simultaneously provides information about their size, location, mobility and attachment site as well as the presence and extent of any consequent hemodynamic effects. How- ever, it is almoust impossible to define tissue character using echocardiography alone, as in our case. Magnetic resonance imaging excels at making a differential diagnosis of various soft tissues and organs becuse of its high revolving power $^{2}$. According to the proper diagnosis the adequate treatment including conservative or surgical approach could be provided.

KEYWORDS: fibroelastoma, echocardiography, atheromatous plaque.

Received: $20^{\text {th }}$ Mar 2013

*Address for correspondence: Klinička bolnica Dubrava, Avenija Gojka Šuška 6 , HR-10000 Zagreb, Croatia.

Phone: +385-1-2902-444

E-mail: drudan3@yahoo.com

\section{Literature}

1. Bicer M, Cikirikcioglu M, Pektok E, Muler H, Dettwiler S, Kalangos A. Papillary fibroleastoma of the left atrial wall: a case report. J Cardiothorac Surg. $2009 ; 4: 28$.

2. Vinkler M, Higgins CB. Suspected intracardiac masses: evaluation with MR imaging. Radiol 1987;165:117-22 